\title{
Achieving high strength in commercial Mg cast alloys through large strain rolling
}

\author{
M.T. Pérez-Prado, J.A. del Valle, O.A. Ruano
}

Dept. of Physical Metallurgy, Centro Nacional de Investigaciones Metalúrgicas (CENIM), CSIC, Avda. Gregorio del Amo, 8, 28040 Madrid, Spain

\begin{abstract}
The room temperature strength of two commercial cast Mg alloys, AZ91 and AM60, processed by severe rolling and accumulative roll bonding (ARB), was investigated. It has been found that a simple onestep large strain rolling process can be used to fabricate sheets that are both extraordinarily strong and remarkably ductile at room temperature. Subsequent rolling passes by accumulative roll bonding (ARB) lead to further (albeit less pronounced) increases in strength without a significant loss of ductility. The strengthening is attributed to the stabilization of a basal-type texture as well as to the occurrence of significant grain refinement.
\end{abstract}

Keywords: Accumulative roll bonding; Magnesium; Severe plastic deformation

\section{Introduction}

Magnesium alloys are attractive candidates for a number of structural applications due to their low density $(1.7 \mathrm{~g} / \mathrm{cm})$ and good machinability. These materials also have other interesting properties, such as an excellent damping capacity and good electromagnetic shielding [1]. An important disadvantage of $\mathrm{Mg}$ alloys, besides having high surface reactivity, is their low strength (compared to other competing structural materials such as Al and steel) and low ductility, which limits their formability. Significant efforts are being devoted lately to engineer stronger and ductile microstructures. Of particular interest is the development of cost-effective processing routes that can be scaled up to meet industrial needs.

Severe plastic deformation (SPD) techniques are proving successful to fabricate ultrafine-grained (UFG) microstructures in a number of metals [2-4]. Moreover, it has been lately reported that some of these UFG materials show, paradoxically, both improved strength and larger ductility with respect to their coarsegrained counterparts [5,6]. Simultaneously, UFG microstructures often exhibit enhanced superplastic behavior [4]. Thus, SPD techniques are promising tools to improve both the strength and the superplastic response of $\mathrm{Mg}$ alloys. Conventional methods of SPD include equal channel angular pressing (ECAP) [7], consisting of passing a billet through an angular die several times, and high pressure torsion (HPT) [8],in which a large shear deformation is imposed in a sample under high pressure. More recently, the method of accumulative roll bonding (ARB) has also been used successfully in a number of materials [9]. Processing of Mg alloys via SPD techniques has only been done so far by ECAP [10-19]. Grain refinement using this technique is in general more pronounced in the alloys with higher amounts of alloying elements and that are processed at temperatures around $200 \mathrm{oC}$.

In a recent paper [20,21], the present authors demonstrated that quite homogeneous UFG microstructures could be obtained in $\mathrm{Mg}$ alloys via severe rolling. Both large strain hot rolling [21], consisting of one pass with a severe thickness reduction, as well as accumulative roll bonding [20], have proved to be efficient methods to fabricate quite homogeneous ultrafine-grained microstructures. The final grain sizes are comparable to those obtained by ECAP. The advantage of severe rolling techniques is that they are 
inexpensive and simple methods that allow forming large sheets of material. Thus, they could be easily put into practice in industry. The aim of this paper is to show the outstanding mechanical behavior of two commercial cast $\mathrm{Mg}$ alloys processed by severe rolling.

\begin{tabular}{lllll}
\hline $\begin{array}{l}\text { Number of } \\
\text { passes }\end{array}$ & AZ91 & & AM60 & $\begin{array}{l}\text { Equivalent Von } \\
\text { Mises strain }\end{array}$ \\
\cline { 2 - 2 } & Reduction (\%) & & Reduction (\%) & \\
\hline 1 & 80 & 80 & 1.9 \\
2 & 80 & & 3.7 \\
3 & 80 & & 5.6 \\
4 & 80 & & 7.5 \\
\hline
\end{tabular}

Table 1 Severe rolling processing parameters

\section{Experimental procedure}

Two Mg cast alloys, AZ91 and AM60, were chosen for this study. The main alloying additions of these materials are 9\% $\mathrm{Al}$ and 1\% $\mathrm{Zn}(\mathrm{AZ} 91)$ and 6\%Al and 0.5\% Mn (AM60). Both alloys were cast from the melt and then solution heat-treated at $425-\mathrm{C} / 1 \mathrm{~h}$ and $450-\mathrm{C} / 30 \mathrm{~min}$, respectively. The solubilized alloys had an equiaxed grain size of $23 \mathrm{Am}$ and $15 \mathrm{Am}$, respectively, as well as a random texture [20,21].

In order to obtain UFG microstructures, severe rolling deformation was imposed in the solution heattreated materials. The rolling scheme followed as well as the resulting microstructures are described in detail in [20,21]. The processing parameters (number of passes and reduction per pass) are summarized in Table 1. In short, the AZ91 alloy was processed via accumulative roll bonding (ARB) at $375-C$, consisting of four rolling passes with $80 \%$ thickness reduction per pass. It was found that the most important microstructural transformations in terms of grain size refinement and texture development take place already during the first pass [20]. An ultrafine grain size $(\mathrm{d}<1 \mathrm{Am})$ is obtained. Increasing the number of passes contributed to developing a more homogeneous microstructure. The AM60 alloy was processed via large strain hot rolling at $375-\mathrm{C}$, with just one rolling pass of $80 \%$ reduction. The average grain size value obtained is $1 \mathrm{Am}$. After processing, both alloys develop a basal-type texture, typical of rolled hcp materials [20,21].

For comparison of the mechanical properties of the severely rolled microstructures with those resulting from other SPD processing routes, both alloys were also ECAPed via route A. The ECAP process consisted of two passes through a 90 -die at $250{ }^{\circ} \mathrm{C}$, after which an equivalent true strain of 2 is achieved. This value is similar to the deformation level reached after one rolling pass with $80 \%$ thickness reduction. The macrotexture of the ECAPed samples on the plane formed by the last extrusion direction (ED) and the transverse direction (TD) (vertical direction) was characterized by X-ray diffraction.

Dogbone tensile coupons with a gage length of $15 \mathrm{~mm}$ were cut out of the initially solution treated materials as well as from the rolled sheets and ECAPed samples. Tensile tests to failure were performed at room temperature at a strain rate of $10^{-3} \mathrm{~s}^{-1}$. The tensile axis was parallel to the rolling direction in the severely rolled samples, and to the last extrusion direction in the ECAPed samples. 

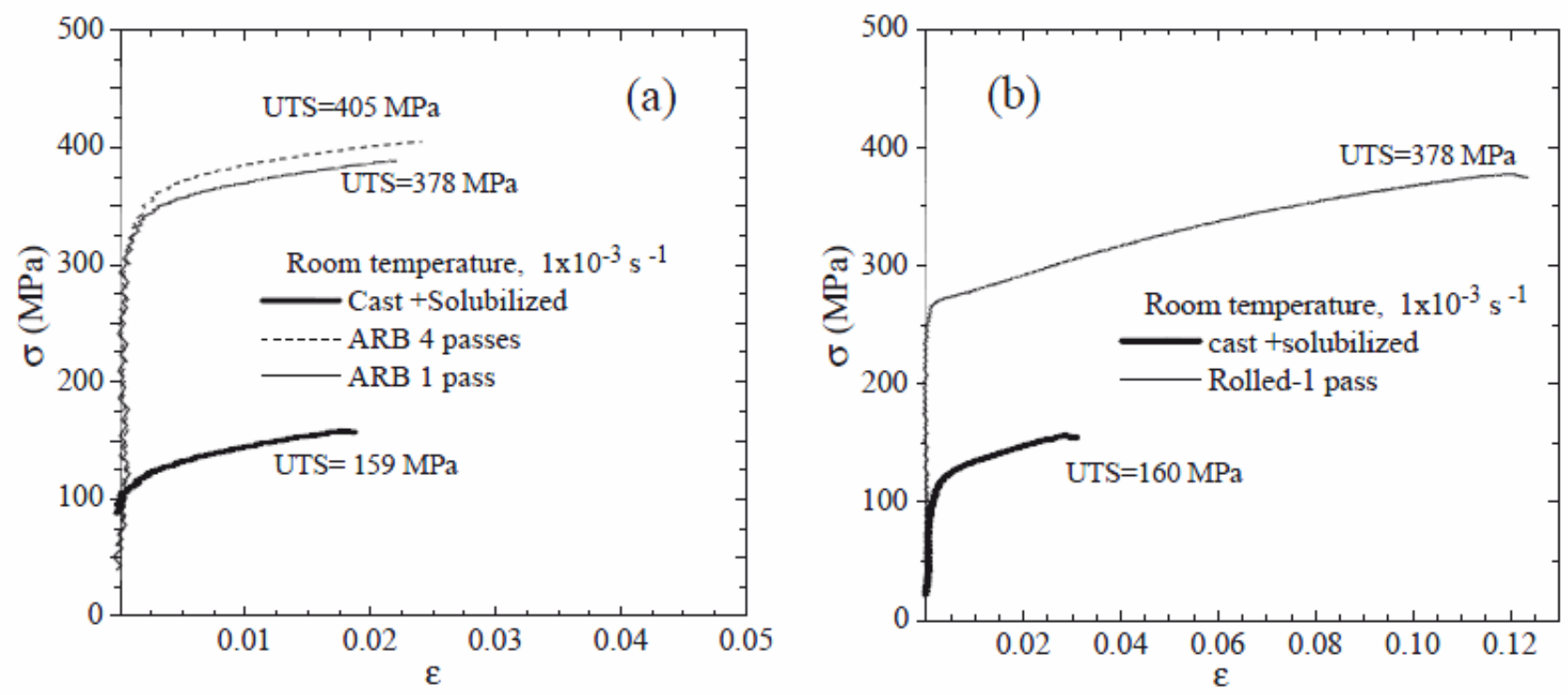

Fig. 1. Mechanical properties at room temperature. Comparison between the solution heat-treated and the rolled materials. (a) AZ91; (b) AM60.

\section{Results and discussion}

Fig. 1 illustrates the stress-strain curves obtained at room temperature and at a strain rate of $10^{-3} \mathrm{~s}^{-1}$ for the AZ91 and the AM60 alloys. The mechanical response of the solution heat-treated (cast and solubilized), coarse-grained materials and the rolled alloys is compared. In both cases the ultimate tensile strength (UTS) corresponding to the rolled samples is about 2.5 times higher than that of the cast and solubilized materials. Moreover, these high strength values are attained without any loss of ductility. In the AZ91 alloy (Fig. 1a) the ductility remains about 2\% both for the SHT and the rolled samples. In the AM60 alloy (Fig. 1b) a remarkable ductility increase from $3 \%$ to $12 \%$ accompanies the strengthening. The simultaneous increase of strength and ductility has been reported in a number of materials processed by severe plastic deformation techniques [5,6]. As illustrated in Fig. 1a, the highest strength increase takes place after the first rolling pass. Successive passes also contribute to further strengthening, but to a much smaller extent.

The notable improvement in the room temperature mechanical behavior of the two cast $\mathrm{Mg}$ alloys studied can be attributed to the simultaneous achievement of a very small grain size (around $500 \mathrm{~nm}$ in AZ91 and $1 \mathrm{Am}$ in AM60) and the stabilization of a basal type texture during severe rolling [20,21]. It is well known that the Hall-Petch slope in Mg alloys is very pronounced $\left(210 \pm 60 \mathrm{MPa \mu m}^{1 / 2}\right.$ vs. $115 \mathrm{MPa}$ $\mathrm{MPa}^{1 / 2} \mathrm{~m}^{1 / 2} \mathrm{Al}$ alloys) [22]. Thus, grain refinement has a significant effect in the mechanical behavior. On the other hand, slip along basal planes is preferentially activated. However, when these planes are oriented parallel to the tensile axis, i.e., when a basal-type texture is present, the critical resolved shear stress (CRSS) increases dramatically, and this leads to a remarkable strength increase.

The UTS values attained in the severely rolled samples are remarkably high for the commercial alloys studied. The strength and ductility values obtained in this investigation are compared in Table 2 with the values reported in the literature for similar $\mathrm{Mg}-\mathrm{Al}$ alloys [12,13,18,23-28]. It can be seen that the combination of very high strength $(>375 \mathrm{MPa})$ and moderate ductility values attained in the present study have never been obtained using a rolling processing route. Similar mechanical property values have been previously achieved mainly only by extrusion or by more expensive and complex processing methods such as powder metallurgy techniques (AZ91(12) in Table 2 [26]), rapid solidification (AZ91(13) [27]), or the 
extrusion and annealing of chips (AZ91(10) [25]).

\begin{tabular}{|c|c|c|c|c|c|c|}
\hline Material & $d(\mu \mathrm{m})$ & Processing method & Strength (MPa) & Ductility (\%) & Strain rate $\left(\mathrm{s}^{-1}\right)$ & Reference \\
\hline AZ91 & $\sim 0.5$ & ARB & 405 & 2 & $10^{-3}$ & This study \\
\hline AM60 & 1.0 & Severe rolling & 378 & 12 & $10^{-3}$ & This study \\
\hline $\mathrm{AZ} 91_{(1)}$ & 2.0 & High ratio extrusion & 350 & 18.0 & $10^{-3}$ & [23] \\
\hline $\mathrm{AZ} 91_{(2)}$ & 1.2 & Extrusion & 400 & 1.9 & $1.7 \times 10^{-3}$ & [24] \\
\hline $\mathrm{AZ91}(3)$ & 2.1 & Extrusion & 302 & 1.4 & $1.7 \times 10^{-3}$ & [24] \\
\hline $\mathrm{AZ} 91_{(4)}$ & 15.6 & Extrusion & 325 & 7.1 & $1.7 \times 10^{-3}$ & [24] \\
\hline $\mathrm{AZ} 1_{(5)}$ & 59.1 & Extrusion & 274 & 11.0 & $1.7 \times 10^{-3}$ & [24] \\
\hline $\mathrm{AZ91}(6)$ & 1.0 & ECAP & 318 & 2.5 & $1.7 \times 10^{-3}$ & [24] \\
\hline $\mathrm{AZ} 91_{(7)}$ & 2.0 & ECAP & 298 & 5.2 & $1.7 \times 10^{-3}$ & [24] \\
\hline $\mathrm{AZ} 91_{(8)}$ & 0.8 & ECAP & 250 & 30.0 & $3 \times 10^{-3}$ & [18] \\
\hline \multirow[t]{2}{*}{$\mathrm{AZ} 1_{(9)}$} & 7.6 & Extruded chips & 343 & 8.0 & $10^{-3}$ & {$[25]$} \\
\hline & & tannealing & 352 & 9.8 & $10^{-3}$ & {$[25]$} \\
\hline \multirow[t]{2}{*}{$\mathrm{AZ91}_{(10)}$} & 15.4 & Extruded chips & 378 & 7.7 & $10^{-3}$ & [25] \\
\hline & & tannealing & 408 & 4.8 & $10^{-3}$ & {$[25]$} \\
\hline \multirow[t]{2}{*}{$\mathrm{AZ91}(11)$} & 66.1 & Extruded chips & 334 & 12.3 & $10^{-3}$ & [25] \\
\hline & & tannealing & 321 & 7.6 & $10^{-3}$ & [25] \\
\hline $\mathrm{AZP1}_{(12)}$ & - & Powder metallurgy & 432 & 6 & - & [26] \\
\hline $\mathrm{AZP1}_{(13)}$ & 0.35 & Rapid solidification & 400 & - & - & [27] \\
\hline$A Z 61_{(1)}$ & 15.0 & ECAP & 302 & 34 & $5 \times 10^{-4}$ & [28] \\
\hline $\mathrm{AZ61}(2)$ & 12.0 & ECAP & 317 & 39 & $5 \times 10^{-4}$ & {$[28]$} \\
\hline $\mathrm{AZ} 1_{(3)}$ & 11.0 & ECAP & 329 & 35 & $5 \times 10^{-4}$ & [28] \\
\hline $\mathrm{AZ} 1_{(4)}$ & 10.0 & ECAP & 317 & 42 & $5 \times 10^{-4}$ & {$[28]$} \\
\hline $\mathrm{AZ} 1_{(5)}$ & 8.0 & ECAP & 310 & 55 & $5 \times 10^{-4}$ & [28] \\
\hline $\mathrm{AZ} 31_{(1)}$ & 2.5 & Severe extrusion & 323 & 50 & $10^{-3}$ & [22] \\
\hline $\mathrm{AZ} 31_{(2)}$ & 15 & ECAP & 270 & 50 & - & [12] \\
\hline $\mathrm{AZZ3}_{(3)}$ & 19 & ECAP & 250 & 45 & $5 \times 10^{-3}$ & [13] \\
\hline
\end{tabular}

Table 2 Comparison of the room temperature properties of several $\mathrm{Mg}-\mathrm{Al}$ alloys processed using different technologies

It can also be inferred from Table 2 that the UTS values obtained in materials processed via ECAP are often significantly lower than those obtained in this study. For example, in the case of the AZ91(8) alloy, which was ECAPed using route $\mathrm{Bc}$, submicron grains are achieved that are comparable to those obtained by severe rolling. However, a much lower UTS value $(250 \mathrm{MPa}$ vs. $\approx 400 \mathrm{MPa})$ is attained. It is well known that, during ECAP using route $\mathrm{Bc}$, the basal planes reorient until they are at 45 -from the extrusion axis (which is usually parallel to the tensile axis) [13-16,28]. Thus, the critical resolved shear stress (CRSS) in these planes is greatly reduced (in comparison to the CRSS of planes that are parallel to the tensile axis as in a basaltype texture) and this leads to a decrease in the UTS. Other alloys in Table 2 processed via route Bc are AZ61(1 - 5) and AZ31(2 - 3). In the latter, however, the grain sizes achieved are significantly larger than those obtained by severe rolling in this study. Thus, the difference in the UTS values with respect to the severely rolled samples can be attributed to a combination of texture and grain size effects.

In order to investigate further the effect of texture on the room temperature strength of the Mg alloys AZ91 and AM60, these materials were processed by ECAP using route A (two passes). This route was chosen because it was found that the resulting textures were similar to those obtained by rolling. Figs. 2 and 3 show the microstructure (Figs. 2a and 3a), (0002) X-ray pole figure (Figs. 2b and 3b), and room temperature stress -strain curves (Figs. 2c and 3c) corresponding to the AZ91 and AM60 alloys, respectively. In both cases it can be seen that the microstructures developed are rather similar to those 
resulting from large strain hot rolling [20,21]. It is noticeable that considerable grain refinement takes place during ECAP. A significant fraction of submicron grains appears in the AZ91 alloy and also a large number of 1-2 Am-diameter grains are formed in the AM60 alloy. The textures of the ECAPed samples are of moderate intensity, with basal planes tending to orient parallel to the extrusion direction, which is also parallel to the tensile axis during uniaxial tests at room temperature. As can be seen in Figs. 2c and 3c, the UTS value of both rolled and ECAPed samples is very similar, which is consistent with the fact that both have basal-type textures of medium intensity and similar grain size values.

Thus, the above results suggest that the remarkably high strength values attained via severe rolling in $\mathrm{Mg}$ alloys could also be achieved by other processing routes, whereby a basal-type texture would develop. The clear advantage of severe rolling is the possibility of fabricating large sheets of very high strength $\mathrm{Mg}$ alloys in one single, rapid, operation. It is foreseen that this processing route could thus be easily adopted by industry in the near future.

(a)

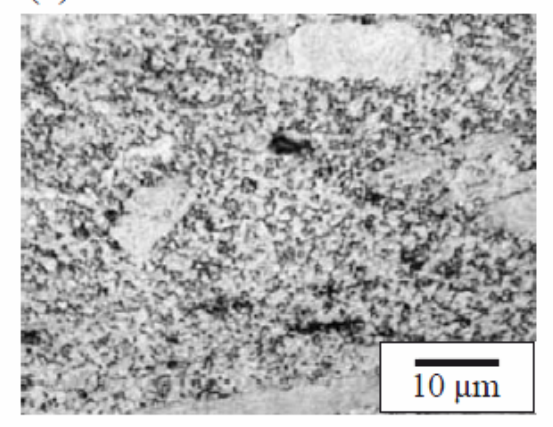

(b)

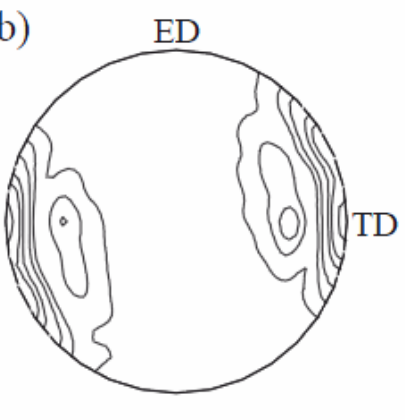

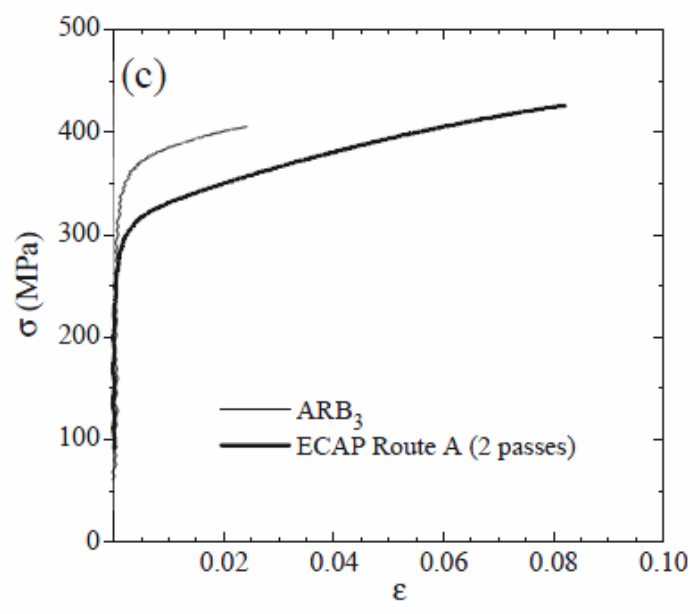

Fig. 2. AZ91 alloy processed by ECAP via route A using two passes. (a) Microstructure; (b) (0002) X-ray pole figure. Levels: $1,2,3 \ldots 8$. ED stands for the last extrusion direction (i.e., the tensile axis in uniaxial tests) and TD is the transverse direction. (c) Comparison of the room temperature mechanical behavior with respect to the sample processed via accumulative roll bonding (ARB3).

(a)

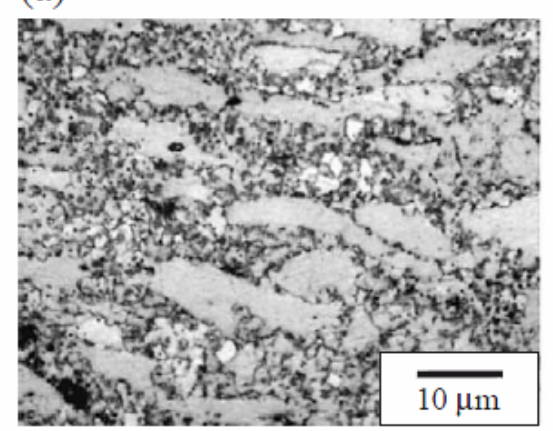

(b)

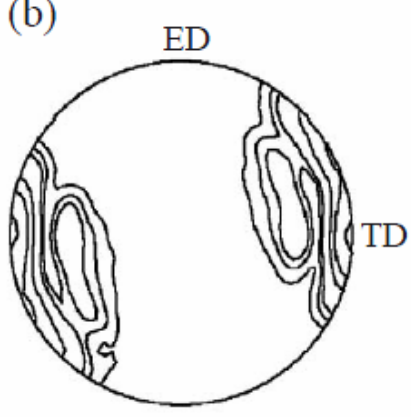

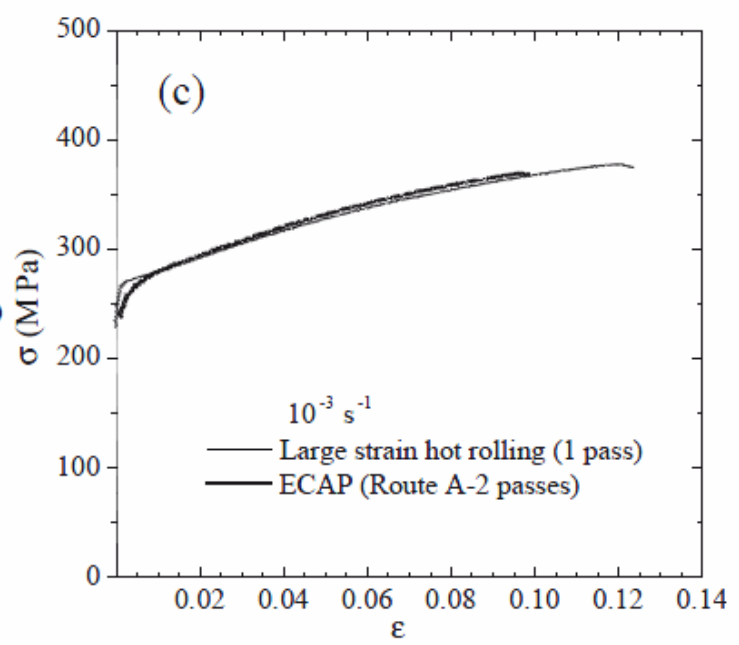

Fig. 3. AM60 alloy processed by ECAP via route A using two passes. (a) Microstructure; (b) (0002) X-ray pole figure. Levels: $1,2,3 \ldots 10$. ED stands for the last extrusion direction (i.e., the tensile axis in uniaxial 
tests) and TD is the transverse direction. (c) Comparison of the room temperature mechanical behavior with respect to the sample processed via large strain hot rolling.

\section{Conclusions}

The room temperature strength of the Mg alloys AZ91 and AM60, processed via large strain rolling and accumulative roll bonding, has been investigated and compared to that of similar materials processed using other available technologies. The following conclusions can be drawn from this study:

1. Severe rolling is a simple, cost-effective method for fabricating very high strength $\mathrm{Mg}$ alloys. After only one pass with $80 \%$ reduction, the strength achieved is over 2.5 times that of the cast alloys, reaching values close to $400 \mathrm{MPa}$. Simultaneously, ductility values are retained or even increased.

2. The high strength achieved is attributed to a combination of both texture and grain size effects.

Acknowledgments

The authors are thankful to Dr. Fernando Carren o for kindly allowing the use of his ECA press for this investigation. Funding from CAM under project GR-MAT0715-2004 is gratefully acknowledged.

\section{References}

[1] Y. Kojima, T. Aizawa, S. Kamado, K. Higashi, Mater. Sci. Forum 419-422 (2003) 3.

[2] P.B. Prangnell, J.R. Bowen, P.J. Apps, Mater. Sci. Eng., A 375 -377 (2004) 178.

[3] R.Z. Valiev, R.K. Islamgaliev, I.V. Alexandrov, Prog. Mater. Sci. 45 (2000) 103.

[4] C. Xu, M. Furukawa, Z. Horita, T.G. Langdon, J. Alloys Comp. 378 (2004) 27.

[5] R.Z. Valiev, Adv. Eng. Mater. 5 (2003) 296.

[6] H.W. Ho“ppel, J. May, M. Go“ken, Adv. Eng. Mater. 6 (2004) 219.

[7] Z. Horita, T. Fujinami, T.G. Langdon, Mater. Sci. Eng. 31 (2001)

34.

[8] A.P. Zhilyaev, G.V. Nurislamova, B.K. Kim, M.D. Baro', J.A. Szpunar,

T.G. Langdon, Acta Mater. 51 (2003) 753.

[9] N. Tsuji, Y. Saito, S. Lee, Y. Minamino, Adv. Eng. Mater. 5 (2003) 338.

[10] A. Yamashita, Z. Horita, T.G. Langdon, Mater. $\quad$ Sci. Eng., A 300 (2001) 142.

[11] K. Matsubara, Y. Miyahara, Z. Horita, T.G. Langdon, Metall. Mater. Trans. 35 (2004) 1735.

[12] T. Mukai, M. Yamanoi, H. Watanabe, K. Higashi, Scr. Mater. 45 (2001) 89.

[13] S.R. Agnew, J.A. Horton, T.M. Lillo, D.W. Brown, Scr. Mater. 50 (2004) 377.

[14] Y. Yoshida, L. Cisar, S. Kamado, Y. Kojima, Mater. Trans. 44 (2003)

468.

[15] W.J. Kim, C.W. An, Y.S. Kim, S.I. Hong, Scr. Mater. 47 (2002) 39.

[16] K. Matsubara, Y. Miyahara, Z. Horita, T.G. Langdon, Acta Mater. 51 (2003) 3073.

[17] M. Mabuchi, H. Iwasaki, K. Yanase, K. Higashi, Scr. Mater. 36 (1997) 681.

[18] V.N. Chuvil'deev, T.G. Nieh, M.Y. Gryazov, A.N. Sysoev, V.I. Kopylov, Scr. Mater. 50 (2004) 861.

[19] H. Watanabe, T. Mukai, K. Ishikawa, K. Higashi, Scr. Mater. 46 (2002) 851.

[20] M.T. Pe'rez-Prado, J.A. Del Valle, O.A. Ruano, Scr. Mater. 51 (2004) 1093. 
[21] M.T. $\quad$ Pe'rez-Prado, J.A. Del Valle, J.M. Contreras, O.A. Ruano, Scr. Mater. 50 (2004) 661. [22] H. Jones, E.J. Lavernia, in: M.A. Otooni (Ed.), Elements of Rapid Solidification, Springer, 1998, p. 135.

[23] H.K. Lin, J.C. Huang, Mater. Trans. 43 (2002) 2424.

[24] Y. Chino, M. Mabuchi, Adv. Eng. Mater. 3 (2001) 981.

[25] M. Mabuchi, K. Kubota, K. Higashi, Mater. $\quad$ Trans., JIM 36 (1995) 1249.

[26] K. Kubota, M. Mabuchi, K. Higashi, J. Mater. Sci. 34 (1999) 2255.

[27] H. Jones, Mater. Sci. Eng., A 137 (1991) 77.

[28] W.J. Kim, S.I. Hong, Y.S. Kim, S.H. Min, H.T. Jeong, J.D. Lee, Acta Mater. 51 (2003) 3293. 